\title{
El uso estratégico del espacio carcelario como elemento referencial de la construcción de identidades en conflicto en el Perú
}

L'usage stratégique de l'espace carcéral comme élément référentiel dans la construction d'identités en conflit au Pérou

The strategic use of prison space as referential element in the construction of conflictive identities in Peru

\section{Camille Boutron}

\section{OpenEdition}

Journals

Edición electrónica

URL: http://journals.openedition.org/bifea/4296

DOI: $10.4000 /$ bifea.4296

ISSN: 2076-5827

Editor

Institut Français d'Études Andines

Edición impresa

Fecha de publicación: 1 mayo 2014

Paginación: 31-51

ISSN: 0303-7495

Referencia electrónica

Camille Boutron, «El uso estratégico del espacio carcelario como elemento referencial de la construcción de identidades en conflicto en el Perú », Bulletin de l'Institut français d'études andines [En línea], 43 (1) | 2014, Publicado el 08 abril 2014, consultado el 05 noviembre 2020. URL : http:// journals.openedition.org/bifea/4296; DOI : https://doi.org/10.4000/bifea.4296

\section{(c) (†) $\odot$}

Les contenus du Bulletin de l'Institut français d'études andines sont mis à disposition selon les termes de la licence Creative Commons Attribution - Pas d'Utilisation Commerciale - Pas de Modification 4.0 International. 


\title{
El uso estratégico del espacio carcelario como elemento referencial de la construcción de identidades en conflicto en el Perú
}

\author{
Camille Boutron*
}

\begin{abstract}
Resumen
La prisión representó un espacio estratégico en el conflicto armado interno vivido por el Perú entre 1980 y 2000. Con la evolución de las leyes antiterroristas, las cárceles peruanas jugaron un papel clave en la lucha contrainsurgente. Adquirieron además un alto capital simbólico que permitió la identificación de los «terroristas» y participaron de la construcción de las identidades históricas del conflicto. Los presos políticos, sin embargo, no se quedaron pasivos frente a estos procesos y en las diferentes etapas del conflicto supieron, a su vez, interiorizar e instrumentalizar el encierro a fin de oponer su resistencia. La cárcel política peruana apareció como un espacio en movimiento perpetuo y un escenario alternativo de conflicto.
\end{abstract}

Palabras clave: espacio carcelario, Sendero Luminoso, represión política, adaptación secundaria, memorias de la violencia

\section{L'usage stratégique de l'espace carcéral comme élément référentiel dans la construction d'identités en conflit au Pérou}

\section{Résumé}

La prison a représenté un espace stratégique au cours du conflit armé vécu par le Pérou entre 1980 et 2000. Avec l'évolution des lois anti-terroristes, les prisons péruviennes ont joué un rôle-clef dans la lutte anti-subversive. De plus, elles ont acquis un fort capital symbolique qui a permis

l'identification des «terroristes» et ont contribué a la construction des identités historiques du conflit. Les prisonniers politiques cependant ne sont pas restés passifs devant le phénomène et ont su, au cours des différentes étapes du conflit, intérioriser et instrumentaliser l'enfermement afin d'opposer leur 
résistance. La prison politique péruvienne est apparue comme un espace en perpétuel mouvement et une scène alternative du conflit.

Mots-clés : espace carcéral, Sentier Lumineux, répression politique, adaptation secondaire, mémoires de la violence

\title{
The strategic use of prison space as referential element in the construction of conflictive identities in Peru
}

\begin{abstract}
Prison acted as a strategic space during the Peruvian armed conflict (1980-2000). With the evolution of anti-terrorism laws, Peruvian prisions have played a key role in the counter-subversive struggle. Plus, they adquired a high simbolic capital which contributed to the making of historical identities of the conflict. Political prisoners nevertheless reacted to the phenomena and knew, all along how to internalize and instrumentalize their imprisonment in order strengthen their resistance. Peruvian political prison appears as a space in constant motion and as an alternative scenario of conflict.
\end{abstract}

Keywords: prison space, Shining Path, political repression, secondary adjustment, memories of violence

El encierro aparece como una práctica clásica cuando se trata de estudiar las diversas formas de represión a lo largo de la historia. Durante mucho tiempo, se ha podido considerar como la primera etapa de un proceso articulado alrededor del castigo corporal cuyo final, generalmente, era la muerte. Quienquiera que lo haya leído se acordará de la descripción, minuciosa y algo lúgubre dada por Foucault, del suplicio infligido a Damiens en las primeras páginas de Surveiller et punir (Foucault, 1975: 25)1. Sin embargo, como el mismo Foucault lo demostró, el encierro como herramienta represiva evolucionó a medida que se iba modernizando el sistema penal de los países europeos al final del siglo XVII, momento el en cual el suplicio, considerado desde ese momento como inaceptable, cede lugar al encierro punitivo y ciertamente «reformador». Este encierro punitivo forma parte de una política de coerción entendida como una de las dimensiones de la «disciplina» dirigida al control de los cuerpos vueltos más dóciles. Sin caer en lo recóndito de los fundamentos teóricos del «biopoder», parece importante recordar aquí cómo la elaboración del sistema penitenciario moderno occidental ha sido parte del proceso más amplio de la institución de relaciones de poder, legitimadas por la capacidad legal de encerrar. El encierro en sí, entonces, aparece como un fenómeno fundamentalmente político, desde el momento que se entiende como parte del funcionamiento de una comunidad. El término «prisión política» surge, ante todo, frente a una necesidad de distinción entre la población constituida por

1 Por haber intentado asesinar al rey Luis XV. 
los individuos encarcelados. En otras palabras, si bien el encierro punitivo aparece como un fenómeno político en sí, la «prisión política» designa una categoría específica de detenidos, es decir, los encarcelados por razones ideológicas, sea por sus opiniones o por los actos que derivan de estas.

Como lo ha subrayado Buntman en el caso del penitenciario de Robben Island en África del Sur durante el Apartheid, la dimensión política del espacio carcelario se encuentra en la construcción de identidades categóricas elaboradas desde la habilidad del «enemigo» para controlar el comportamiento del detenido; esto no solamente en sus relaciones con las autoridades carcelarias sino también con los otros individuos y grupos de encarcelados (Buntman, 1998: 419). Si bien el estatus de «prisionero político» no ha sido objeto de un verdadero reconocimiento legal a nivel internacional, al contrario del de «prisionero de guerra», definido por la Convención de Ginebra (Felices-Luna, 2007: 269), tal designación puede cobrar sentido dentro de los contextos nacionales por el carácter específico del régimen penitenciario aplicado a los individuos detenidos en razón de su militancia política, sus reclamos y formas de organización dentro del espacio carcelario. La idea de poder hablar de la existencia de una prisión política se sostiene, además, por varios ejemplos a lo largo de la historia, particularmente a partir de la segunda mitad del siglo XX, cuando las guerras tradicionales dieron lugar a conflictos intraestatales, como consecuencia de las luchas por la independencia de los países colonizados. De tal manera, durante la guerra de Argelia, el Estado francés reconoció el carácter político de la detención de los militantes del Frente de Liberación Nacional recluidos en la metrópoli (Bellanger, 2007: 165). Otro ejemplo que puede evocarse es el del gobierno británico, el cual entre 1972 y 1976 reconoció a los miembros del Ejército Republicano Irlandés (IRA) como detenidos en el cuadro de su lucha por la independencia, un estatus especial (Special Category Status) que les permitía gozar de ciertas ventajas, distinguiéndose claramente de los presos por delitos comunes (Granger, 2001: 24).

Según el informe final de la Comisión de la Verdad y Reconciliación (CVR), no menos de veinte mil personas fueron encarceladas durante veinte años de violencia política. La mayoría de estas detenciones ocurrieron durante el primer gobierno de Alberto Fujimori, entre 1991 y 1996: en las cárceles del país, indicó que el $66 \%$ de las personas encarceladas habían sido detenidas en dicho periodo. A su vez, ese mismo año aproximadamente dos mil personas todavía cumplían una pena por «delito de terrorismo». Si bien hoy en día esa cifra se ha reducido aproximadamente a seiscientos, los presos políticos representan apenas el 1\% de la población penal total (INPE, 2012: 28). El universo carcelario sigue siendo un elemento importante para entender los diferentes procesos vividos en el Perú dentro de un contexto de posconflicto, mientras que siguen en debate cuestiones vinculadas a las problemáticas fundamentales como la judicialización de los casos de violación de los Derechos Humanos y reparaciones a las víctimas, o a las controversias existentes sobre el nacimiento de movimientos políticos que ponen en evidencia sus lazos con los grupos subversivos como es el caso, por ejemplo, del Movimiento para la Amnistía y los Derechos Fundamentales (Movadef). En 
este contexto la cárcel participa de la construcción de identidades específicas introducidas en los diferentes discursos elaborados alrededor de la violencia política que sufrió el país, permitiendo la identificación de los grupos subversivos protagonistas del conflicto. En cierta medida, se puede decir incluso que la experiencia carcelaria, más que la militancia política, ha podido señalar la figura del combatiente.

En las páginas siguientes, se analizará el universo carcelario peruano bajo esos diferentes aspectos. Podrá verse que en un primer momento ha sido un espacio estratégico de «resolución» del conflicto armado, gracias a la elaboración de normas legales específicas que han permitido la encarcelación de miles de personas durante la época de la violencia política. En este contexto, el periodo marcado por la presidencia de Alberto Fujimori jugó un papel decisivo en la institución del espacio carcelario como forma de identificación y castigo de los militantes subversivos. Se mostrará en un segundo momento cómo este fenómeno ha tenido una verdadera influencia en las subculturas carcelarias que han ido interfiriendo con los eventos exteriores, haciendo de las cárceles verdaderos frentes de batalla. En efecto, la cárcel juega un papel importante en la elaboración de discursos autoritarios y excluyentes, representando un verdadero recurso simbólico en la construcción de las identidades históricas asociadas a la violencia política de ayer y hoy.

\section{EL ESPACIO CARCELARIO COMO INSTRUMENTO DE CRIMINALIZACIÓN DE LA LUCHA ARMADA}

\section{1. 1980-1991: el «delito de terrorismo» y su incorporación al Código Penal peruano}

El Decreto Legislativo n. ${ }^{\circ}$ 46, promulgado en marzo de 1981 durante el gobierno de Fernando Belaúnde, identifica y sanciona el «delito de terrorismo» por primera vez en la historia del país. De manera general reconoce otros tipos de delitos asociados al de terrorismo, como la pertenencia a una organización formalmente reconocida como subversiva o la incitación a la lucha armada. La promulgación de dicho Decreto Legislativo, sin embargo, no estuvo acompañada de medidas legales específicas en comparación con los procesos penales derivados de estos casos y, como consecuencia, la detención y los juicios de los individuos acusados de pertenecer a Sendero Luminoso siguieron el Código de Procedimientos Penales, como se hacía también para los delitos comunes. Esto explica en parte por qué en los primeros años del conflicto armado pocos militantes de Sendero Luminoso (el Movimiento Revolucionario Tupac Amaru [MRTA] todavía no se encontraba activo) fueron sentenciados con penas de cárcel de larga duración. De hecho, las primeras sentencias por terrorismo se dieron en 1982, año en el cual representaron menos del 2\% de los fallos totales; cifra que se triplicaría a partir del año 1984 (Chávez Paz, 1994: 214). Sin embargo, en este momento no se puede hablar de una cooperación real entre las fuerzas del orden enviadas a las zonas de emergencia 
y el sistema penal. Los militares sospechaban que los jueces eran demasiado indulgentes con los subversivos (Uceda, 2004: 67-68). De hecho, entre 1980 y 1985, de 3500 individuos acusados de terrorismo, 300 se encontraban incursos en procesos penales, de los cuales solo 15 habían sido sentenciados (Taylor, 1997: 95), de tal manera que cuadros importantes de Sendero Luminoso fueron interpelados y liberados en varias oportunidades, como es el caso de Laura Zambrano, detenida y absuelta dos veces, en 1985 y 1988, antes de ser detenida en la redada llevada por el Grupo Especial de Inteligencia de la Dirección Nacional contra el Terrorismo (Dincote) en septiembre de 1992 en la casa de Surquillo.

Hubo que esperar hasta el mes de marzo de 1987 para que el Decreto Legislativo promulgado por Belaúnde fuera integrado de manera definitiva en el Código Penal peruano. A partir de ese momento, las detenciones e investigaciones llevadas en el cuadro de la lucha contrasubversiva fueron por primera vez objeto de normas específicas. Se designó al Ministerio Público como principal responsable de las investigaciones llevadas en el contexto de la lucha contra el terrorismo y por primera vez se observó la nominación de jueces especiales para juzgar estos casos. Al mismo tiempo se dio una serie de cambios importantes como los observados en las instituciones policiales que se encontraban en esa misma época en el medio de un proceso de reforma, ya que la Guardia Republicana, la Guardia Civil y la Policía de Investigaciones del Perú (PIP) se unificaron en una sola Policía Nacional. En resumen, si en ese momento el Estado de derecho — al menos teóricamente- siguió siendo respetado en esos procesos, se puede decir que este período representó la primera etapa en la cual se instauraron las estructuras que permitirían, más tarde, la sistematización del uso del encierro penal como instrumento de lucha contra el terrorismo (Rivera Paz, 2007: 95).

\section{2. 1992-2000: sistematización de la criminalización de la protesta social y «judicialización del miedo»}

La llegada al poder de Alberto Fujimori representó una ruptura notable. Mientras en la década de 1980 los militares operaban de manera bastante autónoma respecto a otras instituciones involucradas en la lucha contrasubversiva, el fujimorismo, que obtuvo una parte de su potencia gracias a un control e instrumentalización de sectores claves de las Fuerzas Armadas (como fue el caso del Servicio Nacional de Inteligencia), favoreció un acercamiento estratégico entre las instituciones judiciales y militares, como se muestra en el Decreto Legislativo n. ${ }^{\circ} 734$ emitido el 12 de noviembre de 1991, que autorizaba a las Fuerzas Armadas a controlar los establecimientos penitenciarios en caso de desborde 2 . Tras el autogolpe de 1992, Fujimori poseyó el poder necesario para ampliar los decretos identificando y tipificando el «delito de terrorismo».

2 Decreto Legislativo n. 734 del 12 de noviembre de 1991: se faculta a miembros de las Fuerzas Armadas para ingresar a establecimientos penales en circunstancias que desborden el control del personal encargado de la custodia externa e interna. 
En la época fujimorista se dio la radicalización del Código Penal Peruano como lo muestra la promulgación del famoso Decreto Legislativo n. ${ }^{\circ} 25475$ que retomó la definición del «delito de terrorismo» precisando las normas de los procedimientos de detención, investigación e instrucción. Además, estableció las condiciones en las cuales se debían dar los juicios de los individuos inculpados, así como el régimen penitenciario al cual debían ser sometidos en caso de encontrárseles culpables. La pena mínima de encarcelamiento pasó de diez a veinte años para cualquier individuo reconocido como parte de la cúpula de un grupo subversivo y se estableció para algunos casos la cadena perpetua, muy poco usada en la región. Pero la verdadera «novedad» de este decreto fue que ya no solo sancionaba la participación directa en la lucha armada, sino también todas las actividades de apoyo y militancia. La simple colaboración con un grupo subversivo también se vio castigada con un mínimo de veinte años de cárcel, mientras que la «apología e incitación de la lucha armada» recibían penas de seis a veinte años. Finalmente, la obstrucción de la justicia y la reincidencia eran reprimidas con penas que iban de cinco a diez años para la primera y treinta para la segunda. Al nivel de los procedimientos penales y del régimen penitenciario aplicado a los internos que cumplían pena por «delito de terrorismo», el Decreto Legislativo n. 25745 otorgaba un poder casi ilimitado a la Policía Nacional en lo concerniente a la etapa de investigación preliminar. Un individuo sospechoso de pertenecer a un grupo subversivo podía ser aislado durante un periodo de diez días mientras que la duración legal de la custodia del acusado se prolongaba a quince días. Se crearon cámaras especiales que permitían conservar en secreto los expedientes de las personas detenidas, mientras que salas de audiencias fueron construidas en las mismas cárceles. El acusado no podía distinguir los rasgos de los magistrados «sin rostro», que así podrían preservar su anonimato, gracias a una luz fuerte que impedía reconocerlos. En lo que concierne al régimen penitenciario, los sentenciados por «delito de terrorismo» estaban encerrados en una celda que compartían con otros internos veintitrés horas y media al día. No tenían derecho a acceder a papel, lapiceros o libros y las visitas se limitaban a la de los familiares directos (una vez al mes por el lapso de media hora y a través de locutorios). Estos familiares debían someterse a trámites administrativos complejos y a veces humillantes.

El Decreto Legislativo n. ${ }^{\circ} 25745$ transformó de manera radical el paisaje legal en el cual se dio la inculpación de los individuos sospechosos de pertenecer a uno u otro grupo subversivo. Sin embargo, la criminalización de la lucha armada se consolidó poco tiempo después con la promulgación del Decreto Legislativo n. 25659 que tipificó el delito de «traición a la Patria», a fin de calificar a ciertas actividades reconocidas como «terroristas». En realidad, se retoman los grandes rasgos del Decreto Legislativo $n .^{\circ} 25745$, teniendo como meta particular sancionar el uso y la posesión de armas de fuego o explosivos. Esto explica por qué a partir de esa época muchas personas detenidas en el marco de la lucha contrasubversiva fueron inculpadas por delito de «traición a la Patria», lo que tenía la ventaja de permitir a las Fuerzas Armadas tomar el control de los procedimientos de investigación, instrucción y juicios. 
Estratégicamente, el Decreto Legislativo n. 25659 fue importante para el gobierno fujimorista ya que si la Justicia Militar fue concebida tradicionalmente en caso de guerra externa, su uso en el contexto del conflicto armado interno permitió a las Fuerzas Armadas intervenir oficialmente en la judicialización de la militancia subversiva.

En fin, el Decreto Supremo 015-93 JUS aprobó la ley de arrepentimiento, promulgada por primera vez en mayo de 19923, para que los individuos incursos por delito de terrorismo o traición a la Patria que aceptasen colaborar con las fuerzas del orden pudiesen obtener un mejoramiento de las condiciones de detención, recorte de pena u otro tipo de ventajas. La ley de arrepentimiento, que tenía por objetivo producir deserciones y debilitar las organizaciones armadas, provocó divisiones entre los diferentes grupos de militantes encarcelados. Si el anonimato de la persona que se acogía a la ley de arrepentimiento estaba teóricamente asegurado, la experiencia muestra que los «arrepentidos» se encontraban sometidos al oprobio no solamente de sus antiguos compañeros de lucha sino también de las autoridades penitenciarias. Considerados como soplones, generalmente cambiaban de pabellón y perdían los lazos de solidaridad tejidos en la primera etapa de su detención. La ley de arrepentimiento, pues, aparece como uno de los factores que llevó a la pérdida del poder de confrontación de los presos políticos en las cárceles peruanas y significó un giro importante en sus prácticas de resistencia.

Las leyes antiterroristas, tal como se promulgaron durante la época de Fujimori, permitieron una verdadera radicalización de la judicialización de los delitos de terrorismo en el Perú. Esas estrategias legales tienen similitud a las usadas en Italia durante los años de plomo (Sommier, 2000). Si bien en la década de 1980 las leyes antiterroristas tenían como blanco a los individuos, la serie de disposiciones legales tomadas por el gobierno a partir de 1992 ampliaron la criminalización hacia los familiares, próximos y representantes legales de los acusados de terrorismo. Esa ampliación fue eficiente en la victoria simbólica del Estado peruano sobre los grupos subversivos puesto que debilitó sus redes de apoyo informales. La detención de Abimael Guzmán en septiembre de 1992, seguida por los «acuerdos de paz» negociados entre el líder de Sendero Luminoso y el Estado peruano el año siguiente, significó una nueva etapa en el conflicto armado interno. Si bien varios enfrentamientos se dieron después de la fecha, algunos de ellos bastante espectaculares, la caída de la cabeza de Sendero Luminoso, la criminalización sistemática de la protesta social impulsada por las leyes antiterroristas y la aplicación de un régimen penitenciario que desafiaban las capacidades de la resistencia humana, concretizaron el fracaso de la lucha armada en el Perú. A partir de 1995, los enfrentamientos entre los grupos subversivos y el Estado peruano se focalizaron en zonas aisladas del país; siendo la toma de

3 Decreto Legislativo n. 25499 del 12 de mayo de 1992: se establecen los términos dentro de los cuales se concederán los beneficios de reducción, exención, remisión o atenuación de pena, a incursos en delito de terrorismo. 
rehenes de la residencia del embajador japonés por el MRTA entre 1996 y 1997 la última operación armada de gran envergadura.

Por otra parte, los decretos que permitieron detenciones masivas e indiscriminadas obligaron al propio Fujimori, bajo la presión internacional, a constituir una comisión ad hoc en agosto de 1996, cuya labor fue revisar los casos de personas condenadas injustamente por «delitos de terrorismo y traición a la Patria» y recomendar que se les concediera el indulto presidencial en caso de ausencia de pruebas en su contra. En los tres años que duró su mandato, la comisión permitió la liberación de más de quinientos «presos inocentes» que fueron indultados y excarcelados. Al finalizar su labor, más de mil casos esperaban todavía su revisión. La segunda mitad de la década de 1990 marcó el progresivo fin de las confrontaciones concretas entre los grupos subversivos y el Estado peruano. En ese momento, la cárcel simbolizó un espacio sinónimo de rendición, donde se restablecieron relaciones de poder y autoridad tradicionales. En consecuencia, la sociedad peruana se polarizó entre vencedores y vencidos, y la cárcel representó un espacio de significación donde se reproducían identidades constituyentes de cierta versión de la violencia política. Por otra parte, es necesario subrayar el hecho de que la sistematización de la represión policial y judicial no solo permitió la derrota de los grupos armados sino que también contribuyó a debilitar la sociedad civil organizada. Muchas de las asociaciones de defensa de los Derechos Humanos formadas durante los primeros años del conflicto también se ubicaron en la línea de mira de la represión. Como lo subrayó Burt, el régimen de Fujimori se caracterizó por el uso de una «política del miedo» que permitió otorgar cierto consenso a la coerción ejercida por el Estado (Burt, 2006). La categoría de «terrorista»se amplió para designar a toda persona que expresaba su oposición, o sus dudas, respecto a las medidas adoptadas por el Estado a fin de restablecer el orden. Dirigentes de organizaciones de defensa de Derechos Humanos o de asociaciones de víctimas fueron perseguidos por el gobierno fujimorista: unos fueron encarcelados, otros tuvieron que salir del país, como por ejemplo Angélica Mendoza, dirigente emblemática de la Asociación Nacional de Familiares de Secuestrados, Detenidos y Desaparecidos del Perú (Anfasep). Se observa en el Perú de esa época una «reversión» del proceso democrático iniciado a comienzos de la década de 1980. Gracias a la instauración de un régimen basado en la explotación del miedo, Fujimori logró legitimar y normalizar prácticas de represión cuyos aspectos autoritarios aparecían justificados frente a los diferentes tipos de crisis que tenía que enfrentar el país (Burt, 2004). La cárcel ya no aparecía como un instrumento de regulación de la violencia sino más bien como un instrumento común de gobernabilidad.

\section{3. 2001-actualidad: el espacio carcelario como instrumento de represión de «baja intensidad»}

La caída del régimen de Fujimori significó el regreso del Estado de derecho y permitió un replanteamiento de la revisión de los casos susceptibles de recibir el 
indulto presidencial vía la creación de una nueva Comisión de Indultos en agosto de 2001. El problema de los «inocentes», sin embargo, no se resolvió totalmente en la medida que para la mayoría de ellos los cargos por delito de terrorismo no fueron borrados de sus antecedentes penales. Si el indulto condujo a una liberación y/o al abandono de los cargos penales, no fue suficiente para borrar la etiqueta de «terrorista» que caracterizaba a los indultados cuya recuperación de ciudadanía quedaba entonces incompleta (Faverio \& Naimark, 2013). Los inocentes por otra parte no son el único problema heredado de la época de Fujimori. Hasta el año 2004 se podía contar con más de doce mil personas requisitoriadas por el delito de terrorismo, mientras que existía más de cincuenta y cinco mil requisitorias u órdenes de detención (Enco Tirado et al., 2006: 9). Durante el gobierno de Alejandro Toledo (2001-2006), el trabajo conjunto de las instituciones públicas, sociedad civil y cooperación internacional permitió depurar el porcentaje de requisitorias y sobre todo sensibilizar a los agentes del Poder Judicial frente al problema, mientras que las condiciones que caracterizaban el régimen penitenciario aplicado a los detenidos por delito de terrorismo mejoraron claramente.

Sin embargo, hasta la actualidad, diez años después de la publicación del Informe Final de la CVR, miles de personas siguen requisitoriadas por delito de terrorismo. Por otra parte, si bien la dimensión masiva de las órdenes de captura y, de manera más general, de los procesos judiciales iniciados en contra de los individuos sospechosos de pertenecer a uno u otro grupo subversivo se ha reducido significativamente, las lógicas que determinan la lucha contra el terrorismo en el Perú no han cambiado en lo fundamental. El uso repetido de los decretos de emergencia por Alan García durante su segundo gobierno (2006-2011) aparecen como un reflejo del riesgo de intervención sistemática del Poder Ejecutivo en asuntos relacionados al Legislativo (Blume Rocha, 2011: 88). Mientras esos decretos no conciernen directamente a los procesos políticos y judiciales asociados a casos que relevan «actos de terrorismo», este uso abusivo de los decretos de emergencia deja en evidencia las brechas que siguen afectando el Estado de derecho en el Perú, reflejando la continuidad entre los diferentes mecanismos de autoritarismo que caracterizan la política peruana.

Han sido pocos los verdaderos cambios sobre las lógicas represivas contra el terrorismo en el Perú tras el regreso de la democracia. Si varios de los decretos y leyes promulgados durante el gobierno de Alberto Fujimori han sido derogados, en especial los que afectaban los fundamentos mismos de la democracia - declarados anticonstitucionales-, en el fondo, el tratamiento penal y jurídico del terrorismo (y de manera más general de la protesta social) sigue siendo el mismo. El Decreto Legislativo n. ${ }^{\circ} 25745$ sigue inscrito en el Código Penal peruano, a pesar de la supresión de los aspectos violatorios de los DD. HH. Aunque todas las sentencias emitidas por jueces «sin rostro» fueron anuladas para dar lugar a nuevos procesos judiciales, ninguno de los procesados pudo beneficiarse de la liberación condicional mientras esperaba la nueva sentencia. Además, los mecanismos judiciales para tratar los casos por «delito de terrorismo» no han cambiado en sus conceptos fundamentales: salas especiales, régimen penitenciario específico, condenas extensas. Más de una vez en esos procesos de 
revisión, el procesado recibió la misma sentencia, mientras que en otras ocurrió que el Fiscal apeló el veredicto reclamando una pena mayor para el acusado. En otras palabras, mientras los procesos que caracterizan el trato jurídico del «delito de terrorismo» se adecúan teóricamente a las exigencias de la democracia a partir del 2001 y algunos condenados por «delito de terrorismo» vieron sus condenas sustancialmente reducidas, muchos de los acusados recibieron las mismas penas y hasta mayores. En tales condiciones, la cárcel sigue siendo el único espacio de desmovilización oficial de los actores armados, otorgándoles la mayor responsabilidad de los hechos ocurridos durante el conflicto.

El regreso de la democracia no permitió aflojar las divisiones estrictas entre víctimas y victimarios, los considerados responsables de la violencia y los que han «luchado por la Patria». La cárcel sigue siendo un instrumento clave en las prácticas represivas de los diferentes gobiernos que se suceden en el Perú desde el fin del conflicto armado interno. Si bien el régimen penitenciario mejoró considerablemente desde los años 2000, los presos que cumplían pena por «delito de terrorismo» siguieron siendo sometidos a reglas específicas que limitaban considerablemente sus actividades. Durante el gobierno de Alejandro Toledo, sin embargo, algunos beneficios penitenciarios fueron otorgados a los presos políticos que tuvieron la posibilidad de reclamar su libertad condicional después de haber cumplido las tres cuartas partes de su pena. Además, siete días estudiados o trabajados redimían («borraban») un día de detención. Varios internos lograron salir de la cárcel, como sucedió con Lori Berenson quien salió en abril de 2010 y cuya liberación provocó la rabia de la opinión pública. Su caso no fue el único y fueron varios los que recuperaron su libertad en esa época. En 2009, sin embargo, los beneficios penitenciarios fueron derogados por el gobierno de Alan García y solo pudieron obtenerlos quienes habían empezado sus trámites antes de su abrogación.

El espacio carcelario juega un papel importante en el tratamiento jurídico del «terrorismo» en el Perú y aparece como un elemento de funcionamiento central de las normas establecidas por los diferentes poderes Legislativo, Ejecutivo y Judicial para reprimir la violencia subversiva. Representa también un recurso simbólico, tanto para el Estado como para los grupos subversivos que, cada uno a su vez y de diferente manera, han sabido instrumentalizar este espacio para incluirlo en sus narrativas de lucha.

\section{LOS RECURSOS SIMBÓLICOS DEL ESPACIO CARCELARIO EN LAS MEMORIAS DEL CONFLICTO}

\section{1. El espacio carcelario como prolongación del campo de batalla}

Las prisiones representaron una verdadera prolongación del campo de batalla cuyo control ha sido un desafío para los diversos actores implicados en el conflicto, tanto el Estado como los grupos aislados en armas. Como observa la Comisión de la Verdad y Reconciliación: 
Las cárceles durante los años de violencia política no sólo fueron espacios de detención de procesados o condenados por delitos de terrorismo sino escenarios en los que el Partido Comunista del Perú, el PCP-SL, y en menor medida el Movimiento Revolucionario Túpac Amaru, extendieron el conflicto armado (CVR, 2003, Tomo V: 697).

Desde los primeros años de la violencia política, el espacio carcelario representó una plataforma de acción para el Partido Comunista Peruano Sendero Luminoso (PCP$\mathrm{SL}$ ). Como señala Rénique, el PCP-SL supo elaborar un verdadero «trabajo político carcelario» que se reveló una las dimensiones fundamentales de su insurrección (Rénique, 2003: 17). Este trabajo político carcelario empezó desde las primeras detenciones y muchos de los militantes senderistas iniciaron o consolidaron su formación política mientras estaban presos. Desde el principio, las prisiones se vuelven espacios estratégicos cuyo control permite influir de manera concreta en los acontecimientos del conflicto.

El 3 de marzo de 1983, más de doscientos presos (de los cuales setenta y ocho eran presos «políticos» y ciento sesenta y nueve presos «comunes») se escaparon de la cárcel de Ayacucho. Esa fuga fue famosa en la historia del conflicto armado, no solamente porque fue espectacular — de hecho era el segundo intento y dio lugar a represalias por parte de las fuerzas del orden que incidió de manera directa sobre la estrategia militar antisubversiva en Huamanga-, sino también porque fue ocasión para que figuras como Edith Lagos y Carlota Tello cobraran fama participando en la elaboración de un mito sobre el supuesto compromiso de la juventud con Sendero Luminoso. Si la fuga de la cárcel de Ayacucho fue la más ostentosa, no fue la única que ocurrió durante el conflicto armado interno. Meses antes, catorce detenidos se habían escapado de la cárcel de Pasco mientras que dos reclusas habían logrado escapar del establecimiento penitenciario de Arequipa. Esos casos tal vez no fueron tan espectaculares como el de Ayacucho pero en ambas ocasiones miembros de las fuerzas del orden resultaron heridos o muertos (como en Arequipa) (CVR, 2003, Tomo V: 700).

Las disputas entre el Estado y el PCP-SL para lograr el dominio de las cárceles conoció varios episodios hasta el año 1992, fecha en la cual se reformó la legislación antiterrorista. Durante la década de 1980, los senderistas eran recluidos en el penal de Lurigancho, dentro del pabellón Británico sobre el cual lograron extender su control. Según cuenta Uceda (2004), en 1982 este pabellón albergaba a treinta detenidos por delito de terrorismo y setenta presos comunes. Sin embargo, a medida que los militantes subversivos crecían en efectivos, en 1984 finalmente expulsaron a los presos comunes, a quienes consideraban «inferiores», y reordenaron totalmente su pabellón con pinturas murales que retrataban a Abimael Guzmán, así como el quehacer cotidiano, aplicando una estricta organización de las obligaciones de cada uno: formación política, educación, tareas domésticas, etc. (Uceda, 2004: 151). En otras palabras, los senderistas detenidos en el penal de Lurigancho durante los primeros años de la década de 1980 conquistaron, concretamente, el espacio carcelario para que este último sirva sus intereses. 
Esas maniobras internas se acompañaron de reclamos y enfrentamientos con las autoridades penitenciarias que desencadenaron violencia. En julio de 1985, los detenidos senderistas del pabellón Británico lograron obtener, por parte del entonces director del INPE, una carta firmada en la cual se les reconocía un estatus especial que les daba un espacio de libertad informativa y de expresión. Por otra parte, se les prometió que no serían transferidos al penal de máxima seguridad de Canto Grande. Sin embargo, esas promesas no fueron cumplidas: el Ministro de Justicia cambió al director del INPE permitiendo así a la nueva autoridad (Manuel Aquézolo) pasar por alto los acuerdos firmados. Durante una requisa realizada en octubre de 1985, un primer enfrentamiento brutal ocurrió entre los presos senderistas y las autoridades penitenciarias que provocó la muerte de más de treinta personas y la destrucción del pabellón (Uceda, 2004: 152). Ante esta acción del Estado, los senderistas respondieron con el asesinato del director de El Frontón, Miguel Castro Castro, y a partir de este momento, se dio un escalamiento de la violencia que terminó en las masacres de los penales en junio de 1986, que dejaron más de doscientos muertos.

El penal de Lurigancho, sin embargo, no fue el único en el cual estallaron conflictos entre presos políticos y autoridades. En el caso de El Frontón, un establecimiento penitenciario ubicado en una isla del Callao y que, después de su cierre en la década de 1970 había sido reabierto especialmente para albergar a militantes senderistas, varios enfrentamientos ocurrieron entre presos y autoridades desde fines de 1982. Esas movilizaciones también fueron observadas en otras cárceles del país, en Huancavelica, Huánuco o Trujillo y el espacio carcelario se volvió un verdadero escenario de protesta (Rénique, 2003: 61). En poco tiempo, el control carcelario había escapado de las manos del Estado. Los motines simultáneos de los tres penales de Lima y Callao en junio de 1986 representaron una oportunidad de «acabar» con esa resistencia: los senderistas detenidos en los penales de Santa Bárbara (de mujeres), Lurigancho y El Frontón aprovecharon un encuentro político de la Internacional Socialista que tenía lugar en Lima para amotinarse. La respuesta militar que el Estado desarrolló aniquiló a la subversión. Si bien esto no significó el fracaso definitivo de las acciones llevadas por el PCP-SL dentro y desde las cárceles, este momento marcó el fin de las negociaciones entre los detenidos políticos y las autoridades penitenciarias.

Las acciones llevadas por el MRTA fueron más discretas. De hecho, la ideología defendida por este grupo no daba tanta importancia al «trabajo político carcelario» como lo hacía Sendero Luminoso. Sin embargo, la espectacular fuga del dirigente del MRTA, Víctor Polay, seguido por una cuarentena de militantes en julio de 1990, representa una de las acciones más impactantes del MRTA cuyos integrantes supieron usar el escenario del espacio carcelario como plataforma de acción.

En la década de 1990, sin embargo, la cárcel adquirió una dimensión simbólica que iba a dejar sus huellas en la memoria colectiva del conflicto. 


\section{2. La cárcel como instrumento de estigmatización y marginalización}

La cárcel ha sido objeto de ficciones literarias que no conciernen exclusivamente la época del conflicto armado. Novelas como El Sexto (1961), para la cual Arguedas se inspiró en su encarcelamiento entre 1937 y 1938 durante la dictadura de Oscar R. Benavides, han ilustrado la larga tradición del encierro como una forma de reprimir partidos políticos indeseables. Sin embargo, como lo ha subrayado Tauzin-Castellanos, si la evocación de la cárcel ha sido recurrente en la literatura peruana, esto se intensifica después del conflicto armado interno (Tauzin-Castellanos, 2008). El universo carcelario ejerce una forma de fascinaciónrepulsión que dice mucho sobre la relación que tiene la sociedad peruana con su historia reciente. La prisión actúa en realidad como un espacio de referencia y permite la construcción de una identidad específica, la del «terrorista». Puesto que ya no se cuenta con acciones armadas que atraigan la atención de la opinión pública, la cárcel permite «recordar» el peligro. La cárcel ha permitido a la fuerzas del orden retomar un control sobre cuerpos y mentes, y eso ha implicado un conjunto de prácticas y discursos específicos. Por otra parte, y como se ha visto anteriormente, la encarcelación de los militantes subversivos es legitimada por la elaboración de un conjunto de disposiciones legales que permiten la criminalización de sus acciones y del movimiento al cual pertenecen (FelicesLuna, 2007: 270). En ambos casos la cárcel no solo actuó como un sistema, sino también como un campo referencial.

No solo la cárcel sino también las mismas condiciones de reclusión han representado herramientas de represión durante el conflicto armado interno. El régimen penitenciario dirigido a los presos por «delito de terrorismo» en la década de 1990 tenía por objetivo quebrar física y sicológicamente la voluntad de los militantes subversivos, por lo tanto su capacidad de resistencia. El penal de Yanamayo, en las alturas de Puno, encarna esas prácticas de «tortura indirecta» desarrolladas por el Estado a fin de reprimir la subversión. Ubicado lejos de la capital, a $5000 \mathrm{msnm}$, las condiciones de vida en la prisión eran restrictivas y destructivas. Internos que pasaron un tiempo en Yanamayo dieron su testimonio a la CVR, resaltando la falta de higiene, salud y trato digno (CVR, 2003, Tomo V: 717). Las torturas físicas, violaciones y humillaciones sexuales, sobre todo en el caso de las mujeres (Aprodeh, 2002) y la presión ejercida sobre familiares, aparecen en las prácticas desarrolladas en el espacio carcelario, cuya meta fue romper los lazos de militancia política. Esta estrategia dio resultado cuando se decretó la ley de arrepentimiento que permitía una abreviación de pena o, justamente, un mejoramiento de las condiciones de detención:

Vivíamos dos personas en una celda... para asearnos. Lo usábamos para lavar los utensilios que usábamos para comer y después para echar en el baño, porque ahí mismo nos ocupábamos del baño (...) (CVR, testimonio n. ${ }^{\circ} 700020$ ). 
Me tiraron al piso y me quitaron toda la ropa (...) (CVR, testimonio n. ${ }^{\circ}$ 700563).

Me amenazaban con violarme... me metían la mano en mis partes genitales y no uno, varios (...) (CVR, testimonio n. ${ }^{\circ}$ 700056).

Si bien las condiciones de detención mejoraron considerablemente desde el regreso de la democracia, la cárcel sigue representando un lugar de desecho. Los discursos que regulan la encarcelación de los militantes de los grupos subversivos establecen una continuidad entre la época del conflicto armado y la actualidad. Al leer la prensa, por ejemplo, el tema de la liberación de los condenados por «delito de terrorismo» que cumplen con el fin de su condena hace surgir preocupaciones, entre ellas la supuesta «protección» de la sociedad contra un eventual rebrote de las acciones armadas. Es interesante ver que la cárcel no es considerada como un espacio dentro del cual se puede «reformar» a las personas, sino más como instrumento para proteger a la «buena sociedad». Los discursos de masa, así como los usos más concretos que se hacen del espacio carcelario en el Perú, reflejan el desencuentro profundo entre los diferentes grupos sociales que forman la sociedad peruana.

Las no tan lejanas liberaciones de detenidos por «delito de terrorismo» provocaron ira en la opinión pública urbana de clase media. Aquí lo interesante no es tanto estudiar los discursos de la prensa en sí, sino aquellos comentarios dejados en la web por lectores de periódicos como El Comercio o La República. A la salida de Lori Berenson en 2010, numerosos fueron los internautas que expresaron su oposición, a tal punto de emplear términos extremadamente violentos. Así en respuesta a un artículo en línea de El Comercio del 16 de agosto de 2010, en el cual Lori Berenson pidió perdón por su actividad terrorista y descartó ser «peligro para la sociedad»4, muchos usuarios se manifestaron de manera agresiva:

«Erospk2»: Todos tienen derecho a una segunda oportunidad, pero creo que hay excepciones y este caso es una de esas excepciones, al igual que asesinos, violadores y cualquier otra lacra que atente contra la humanidad deben permanecer en la cárcel... ya es hora de aprobar la pena de muerte para estas lacras.

«Shantimita»: Colaboró con terroristas, eso es suficiente! (...) No me interesa su arrepentimiento, de nada sirve después de tanta muerte y sufrimiento que causó el MRTA al que apoyó. Simplemente que la expulsen del Perú, que se vaya!

«Gabanto»: Pero, ipor qué demoran tanto en expulsar a esa individua?

Estas expresiones de asco no son lanzadas al azar. En este caso, y en muchos otros, en el cual se evoca por alguna razón a uno o varios individuos que cumplen pena por «delito de terrorismo», se recurre al campo lexical específico dentro del cual las nociones de «expulsión», «rechazo», «eliminación» aparecen regularmente

4 Disponible en: http://elcomercio.pe/politica/624151/noticia-lori-berenson-pidio-perdon-actividadterrorista-descarto-peligro-sociedad 
asociadas a la idea de «suciedad», «vicio», «lacra». Esos comentarios, por más anónimos e informales que sean, traducen el rechazo de la parte dominante de la sociedad peruana hacia toda persona que haya sido detenida por «delito de terrorismo». Este tipo de dinámica recuerda el concepto de «basurización simbólica», tal como lo desarrolla Rocío Silva para describir la forma en la cual «el otro [se ve organizado] como un elemento sobrante de un sistema simbólico, en este caso la nación peruana, a partir de conferirle una representación que produce asco» (Silva Santisteban, 2008: 17). Ahí se puede notar cómo la prisión actúa como un espacio referencial que produce justifica y legitima no solamente el rechazo sino sus expresiones en términos de «asco». No se cree que este uso del encierro penal se limite a la subversión política. Vale aquí recordar las perspectivas generales que se tienen desde las élites socioeconómicas urbanas de los militantes del PCP-SL y MRTA, asimilados a poblaciones marginalizadas. La cárcel por sus usos concretos y también por los discursos que produce, permite la circulación de un lenguaje de rechazo definitivo y formal que, ejerciendo su función de sustracción física y estigmatización, actúa como un «hueco de memoria» (Artières et al., 2004).

\section{3. La cárcel como elemento referencial en las memorias del conflicto armado peruano}

La sociología carcelaria francesa subraya el hecho de que la figura del «criminal» es construida por el encierro y no por el delito (Combessie, 2008: 233). Poco importa la condena en realidad si no se acompaña de una pena de cárcel efectiva que permita la identificación formal del «mal». Según autores como Combessie, es la «toma de cuerpo» (prise de corps), o sea la coerción física inducida por el encierro, la que sobrentiende la responsabilidad del criminal (Combessie, 2008: 236). Desde este punto de partida se entiende cómo el espacio carcelario se constituye en un referencial para el Estado peruano, que lo usa para identificar y ubicar a los responsables de la violencia política. Mientras representa una verdadera «muerte civil», la prisión actúa como un elemento de contención frente a los cuestionamientos que pueden surgir en el escenario del posconflicto. Puede darse un ejemplo a partir de las cuestiones que surgieron en el Consejo Nacional de Reparaciones (CNR) cuando se trató de abrir el proceso de inscripción en el Registro Único de Víctimas (RUV). A pesar de que los miembros de la CVR habían ido a las cárceles para entrevistarse con más de mil detenidos por «delito de terrorismo» en fin de reportar los casos de violaciones de los Derechos Humanos ocurridos durante la detención, se decidió excluir a toda persona condenada por «delito de terrorismo» de la posibilidad de inscribirse en el RUV. Sin embargo, y como se verá más adelante, los arrestos, interrogatorios y condiciones de encarcelamiento estuvieron marcados por prácticas de violencia que todavía no han suscitado más investigaciones que aquellas entrevistas realizadas en el año 2002 por la CVR. Si los abusos realizados a los militantes subversivos detenidos por las fuerzas del orden son hechos conocidos, no son reconocidos formalmente 
en el ámbito judicial nacional. La cárcel actúa a la vez como un marcador y un filtro. La condena por «delito de terrorismo» se convierte en un verdadero estigma para el condenado que se ve íntima, simbólica y corporalmente marcado por el encierro que lo identifica como parte de los responsables.

Por otro lado, este estigma limita la posibilidad de deconstrucción de la polaridad que caracteriza a la sociedad peruana posconflictual, dividida entre los «perpetradores» y las «víctimas», dos identidades antagónicas que no sufren yuxtaposición a pesar de que en muchos casos determinar con precisión la frontera entre víctimas y victimarios aparece como una tarea casi imposible. Autores como Utas (2005: 408) han mostrado cómo los individuos confrontados a situaciones de violencia (su trabajo empírico tiene como escenario África del Este) podían a su vez asumir diferentes roles y navegar de un grupo al otro, lo que puede en algunos casos inducir la confusión entre víctimas y victimarios. En el caso del Perú, la cárcel permite mantener una distancia entre ambos grupos, rechazando la idea de que pueda existir un espacio intermedio entre ellos. Esa división además es respetada por la mayoría de los grupos de actores involucrados en el posconflicto, asociaciones de Derechos Humanos, movimientos políticos, organizaciones de la sociedad civil y opinión pública. Como se ha visto, el capital simbólico que trae el espacio carcelario supera los límites infraestructurales judiciales para actuar como una verdadera referencia en la memoria colectiva del conflicto, impidiendo cuestionar la repartición de las responsabilidades.

Si la prisión es sinónimo de represión, también se presenta como un lugar donde se organizan frentes de resistencia. En este sentido, la cárcel aparece como un espacio que participa en la construcción de memorias y narraciones políticas e individuales específicas sobre la violencia política. Sin embargo, hasta el conflicto armado interno, ningún grupo político había integrado el espacio carcelario dentro de su ideología y estrategias como lo ha hecho el PCP-SL (Rénique, 2003: 16-17). Los presos políticos, sin embargo, no se quedaron pasivos frente a ese fenómeno y elaboraron estrategias de resistencia desarrolladas desde el mismo repertorio del encierro. En la actualidad se puede decir que esas luchas prosiguen a pesar de que el rol del espacio carcelario se ha vuelto más «referencial». Después de la matanza en los penales y de la llegada al poder de Alberto Fujimori, si bien los presos por «delito de terrorismo» perdieron toda posibilidad de adquirir un estatus específico que los diferenciara de los presos comunes, siguen identificados e identificándose como un grupo «especial». La dimensión política de su encierro, a pesar de su informalidad, representa y guía la organización social cotidiana de los presos y a su vez significa una forma de resistencia a las limitaciones impuestas por el encierro, lo que les permite demarcarse de los presos comunes. Hasta se puede hablar de una forma de «conquista» del espacio carcelario por parte de los presos por «delito de terrorismo» que también lo usan como referencial para definir su identidad. En los penales de máxima seguridad como Castro Castro (varones) y Chorrillos II (mujeres), los detenidos están repartidos según su afiliación (o desafiliación) política. Si bien este no siempre ha sido el caso y sabiendo que las autoridades muchas veces jugaron con las rivalidades entre 
el PCP-SL y el MRTA, se puede decir que los internos ejercen cierto control territorial sobre sus pabellones, talleres, patios y celdas, disponiendo de un amplio margen de libertad en el ordenamiento de estos espacios. A pesar de que estas últimas observaciones también son válidas para los presos comunes —como lo demuestra el trabajo de Pérez Guadalupe (2000) sobre el penal de Lurigancho_-, en el caso de los presos políticos este control conlleva una dimensión ideológica y política que tiene por objetivo subrayar la demarcación con los otros presos, rechazando el estatus de «delincuente» otorgado por el encierro. Esas dinámicas permiten en cierta medida establecer una continuidad entre la lucha política y la resistencia al encierro.

Estas resistencias son numerosas y diversas, además adoptan formas muy diferentes según el género. Durante el conflicto armado los presos han logrado organizarse en varias ocasiones a fin de reclamar sus derechos, realizar huelgas de hambre o contactarse con la prensa u otros medios para atraer la atención sobre las condiciones de su encierro. De manera general, actualmente existe cierta homogeneidad en la forma de «habitar» el espacio carcelario por parte de los presos políticos. El orden y respeto de los valores morales son elementos fundamentales de la organización cotidiana que permiten expresar una «superioridad»sobre los demás presos; así como en las diferentes actividades realizadas en la cárcel donde el arte ocupa un lugar central. Sea individual o colectivamente, los presos políticos, especialmente los del PCP-SL, han logrado producir diferentes tipos de creaciones: literarias, artesanales, performance, que han logrado superar física y simbólicamente las paredes de la cárcel. Por otra parte, existen numerosas organizaciones, muchas de ellas formadas por familiares o ex detenidos, que brindan apoyo a los presos políticos. Algunas de ellas, como la Asociación de Familiares de Presos Políticos, Desaparecidos y Víctimas del Genocidio (Afadevig), se inscriben en redes complejas y transnacionales que les permite seguir luchando por los casos Ilevados a la Corte Interamericana de los Derechos Humanos, como ha sido el caso de la matanza ocurrida en mayo de 1992 en el penal Castro Castro. Otras organizaciones apolíticas — como la Cruz Roja - han podido defender los derechos de los internos, mientras que una diversidad de individuos, muchos de ellos extranjeros (investigadores, miembros de comités de apoyo, religiosos cristianos) también gravitan alrededor de los presos políticos.

El repertorio de acción de los detenidos por «delito de terrorismo» es bastante amplio y merecería ser más detallado y analizado. Sin embargo, estos ejemplos y observaciones permiten mostrar que la cárcel política merece su adjetivo no solamente porque representó, y sigue representando, una herramienta para la represión de los grupos subversivos en manos del Estado peruano, sino que también se ha constituido desde los primeros años del conflicto en una plataforma de movilización. Esa última, que toma varios aspectos según el periodo y los lugares, aparece como una forma de «adaptación secundaria» tal como la conceptualiza Goffman en su clásico libro Asylums (Goffman, 1962). Mientras que la «adaptación primaria» significa una aceptación del interno de las reglas que se le imponen durante el encierro, la «adaptación secundaria» significa una 
capacidad de interiorizar e instrumentalizar esas reglas para ganar espacios de libertad y márgenes de acción. Si bien varios estudios intentaron conceptualizar y categorizar las diferentes formas de adaptación secundaria (Khiat, 2010: 158), todavía no han sido realmente enfocadas desde una dimensión política ni desde una escala que supere los límites físicos de la prisión. La evolución del espacio carcelario como forma de «resolución» del conflicto armado peruano muestra, sin embargo, que esa perspectiva representa un aporte significativo para entender el papel jugado por sus diferentes usos en contextos de «posconflicto».

\section{CONCLUSIÓN}

La adaptación del sistema penal peruano a las lógicas contrainsurgentes adoptadas por el Estado aparece como un proceso que empieza en la década de 1980. Esta dimensión histórica permite entender cómo el recurrir al encarcelamiento penal ha podido instituir el espacio carcelario como una de las principales infraestructuras de «regulación» de la violencia política en el país. El uso de la cárcel como herramienta de represión e instrumento de «contención» de la protesta social sigue vigente hoy en día, a pesar del regreso de la democracia y del trabajo realizado por la CVR. El espacio carcelario representa un lugar de olvido, un «hueco de memoria», un escondite.

Dicho espacio, sin embargo, también representó un escenario alternativo de la movilización política. Como lo subraya Linhart en el caso de las cárceles alemanas en la década de 1970, las cárceles políticas encarnaron «arenas alternativas del conflicto» (Linhart, 2004). Esas observaciones, por lo tanto, valen también en el contexto de posconflicto. Si bien el espacio carcelario impone límites estructurales difíciles de delimitar, produciendo una fuerte estigmatización social, también es un lugar en el cual se puede observar cierta continuidad de la lucha reivindicada como «revolucionaria»y la constitución de redes de actores que logran influir en este escenario.

El espacio carcelario aparece como una especie de regulador de memorias. En un primer momento, permite establecer una identificación de los presuntos responsables de la violencia. En el contexto del posconflicto se ha vuelto también un símbolo de justicia. En el año 2009, un momento clave ha sido la condena de Alberto Fujimori a 25 años de prisión por el delito de violación de los Derechos Humanos. Que el Perú haya adoptado normas internacionales inspiradas en las diferentes experiencias de justicia transicional, asociadas con esfuerzos locales de búsqueda de verdad y justicia, ha permitido abrir una nueva reflexión sobre la repartición de las responsabilidades de los diferentes grupos de actores implicados en la violencia (Burt, 2009). Sin embargo, se constata que estos eventos no bastaron para romper con la polaridad entre víctimas y victimarios, héroes y enemigos, que estructuran la sociedad peruana posconflictual. Existe en realidad una diferencia entre el rol que pueden jugar los diversos procesos judiciales iniciados desde la publicación del informe final de la CVR y el significado concreto que otorga el 
espacio carcelario a los individuos que recluye. Como lo subrayaba Osiel (2006), mientras el juicio aparece como un espacio de expresión (y regulación) de memorias traumáticas, la cárcel, que otorga de manera definitiva la identidad de culpable, también viene a cerrar todo tipo de debate. El espacio carcelario, contrariamente a los juicios, representa una forma de conclusión, extrayendo al individuo del espacio público donde se dan las diferentes performances de memoria, verdad y justicia. Si bien una de las finalidades del juicio es permitir la reconciliación, la cárcel sigue siendo usada como instrumento de represión y exclusión. La detención de dirigentes de las actuales movilizaciones sociales en el cuadro de los conflictos socioambientales tiende a demostrar que el espacio carcelario sigue representando la forma legítima de contención de la protesta social en el Perú.

\section{Referencias citadas}

ARTIÈRES, P., LASCOUMES, P. \& SALLE, G., 2004 - Prison et résistances politiques. Le grondement de la bataille. Cultures \& Conflits, 55: 5-14.

ARGUEDAS, J. M., 1961 - El Sexto, 198 pp.; Lima: Editorial J. Mejía Baca.

ASOCIACIÓN PRO DERECHOS HUMANOS (APRODEH), 2002 - Al otro lado de la libertad. Testimonios de mujeres en cárcel, 40 pp.; Lima: APRODEH.

BELLANGER, H., 2007 - Vivre en prison. Histoires de 1945 à nos jours, 334 pp.; París: Hachette Littératures.

BLUME ROCHA, A., 2011 - Los decretos de urgencia de Alan García: el abuso y la usurpación de la facultad legislativa por parte de Poder Ejecutivo, 144 pp.; Lima: Instituto de Defensa Legal-Justicia Viva.

BUNTMAN, F. L., 1998 - Categorical and Strategic Resistance and the Making of Political Prisoner Identity in Apartheid's Robben Island Prison. Social Identities, 4 (3): 417 441.

BURT, J.-M., 2004 - State-making against democracy: the Case of Fujimori's Peru. In: Politics in the Andes: identity, conflict, reform (J.-M. Burt \& P. Mauceri, eds.): $247-$ 268; Pittsburgh: University of Pittsburgh Press.

BURT, J.-M., 2006 - «Quien habla es terrorista»: The Political Use of Fear in Fujimori's Peru. Latin America Research Review, 41 (3): 32-62.

BURT, J.-M., 2009 - Guilty as Charged: The Trial of Former Peruvian President Alberto Fujimori for Human Rights Violations. The International Journal of Transitional Justice, 3 (3): 384-405.

CHÁVEZ DE PAZ, D., 1994 - Juventud y terrorismo. Características sociales de los condenados por terrorismo y otros delitos. In: Perú en el fin del milenio $(\mathrm{H}$. Bonilla, ed.): 211-248; México: Consejo Nacional para las Artes y la Cultura.

COMBESSIE, P., 2008 - Paul Fauconnet et l'imputation pénale de la responsabilité: une analyse méconnue mais aujourd'hui pertinente pour peu qu'on la situe dans le 
contexte adéquat. In: Anamnèse $n .^{\circ}$ 3. Trois figure de l'école durkheimienne: Célestin Bouglé, Georges Davy, Paul Fauconnet (C. Ravelet, ed.): 221-246; París: L'Harmattan.

COMISIÓN DE LA VERDAD Y RECONCILIACIÓN (CVR), 2003 - Informe Final, 9 tomos.

ENCO TIRADO, A., RIVERA PAZ, C., SALAZAR GARCÍA, A. \& VALLE MANCHEGO, T., 2006 - Los requisitoriados por terrorismo. ¿Quiénes son? ¿Cuántos son? Cumpliendo las recomendaciones de la Comisión de la Verdad, 236 pp.; Lima: Instituto de Defensa Legal.

FAVERIO, A. \& NAIMARK, A., 2013 - Perpetual Injustice: The Twenty-Year Battle for Reparations in Peru. Human Rights Brief, 20 (3): 32-36.

FELICES-LUNA, M., 2007 - The Neutralization, Rehabilitation or Responsibilization of Dissidents, Subversives and Terrorists. In: Actes du colloque international Le pénal aujourd'hui : pérennité ou mutations: 268-276.

FOUCAULT, M., 1975 - Surveiller et punir, 318 pp.; París: Gallimard.

GOFFMAN, E., 1962 - Asylums: essays on the social situation of mental patients and other inmates, 386 pp.; Chicago: Aldine Pub.

GRANGER, T., 2001 - Une stratégie de I'IRA: la lutte en prison (1971-1981). Vingtième siècle. Revue d'histoire, 70: 19-30.

INSTITUTO NACIONAL PENITENCIARIO (INPE), 2012 - Informe estadístico; Lima: Consejo Nacional Penitenciario - Unidad estadística.

KHIAT, H., 2010 - Secondary Adjustment in prisons: prisoners' strategies of influence. Qualitative Sociology Review, 6 (2): 147-159.

LINHART, D., 2004 - Réclusion révolutionnaire. La confrontation en prison entre des organisations clandestines révolutionnaires et un Etat. Le cas de l'Allemagne dans les années 1970. Cultures \& Conflits, 55: 113-148.

OSIEL, M., 2006 - Juger les crimes de masse. La mémoire collective et le droit, 453 pp.; Seuil: París.

PÉREZ GUADALUPE, J. L., 2000 - La construcción social de la realidad carcelaria. Los alcances de la organización informal en cinco cárceles latinoamericanas: Perú, Chile, Argentina, Brasil y Bolivia, 436 pp.; Lima: Pontifica Universidad Católica del Perú.

RÉNIQUE, J. L., 2003 - La voluntad encarcelada: las «luminosas trincheras de combate» de Sendero Luminoso del Perú, 177 pp.; Lima: Instituto de Estudios Peruanos.

RIVERA PAZ, C., 2007 - Ley penal, terrorismo y Estado de derecho. Quehacer, 167: 68-75.

SILVA SANTISTEBAN, R., 2008 - El factor asco. Basurización simbólica y discursos autoritarios en el Perú contemporáneo, 195 pp.; Lima: Pontificia Universidad Católica del Perú, Universidad del Pacífico, Instituto de Estudios Peruanos.

SOMMIER, I., 2000 - Repentir et dissociation: la fin des «années de plomb» en Italie ? Cultures \& Conflits, 40: 43-61.

TAUZIN-CASTELLANOS, I., 2008 - Las cárceles peruanas y su ficcionalización: una imagen del Perú contemporáneo. In: Prisons d'Amérique Latine : du réel à la métaphore de I'enfermement (I. Tauzin-Castellanos, ed.): 135-170; Bordeaux: Université Michel de Montaigne.

TAYLOR, L., 1997 - La estrategia contrainsurgente, el PCP-SL y la guerra civil en el Perú 1980-1996. Debate Agrario, 26: 81-110.

UCEDA, R., 2004 - Muerte en el Pentagonito. Los comentarios secretos del Ejército Peruano, 477 pp.; Bogotá: Planeta. 
El espacio carcelario como elemento referencial de la construcción de identidades en conflicto en el Perú

UTAS, M., 2005 - West-African warscapes: vitimicy, girlfriending, soldiering: tactic agency in a young woman's social navigation of the Liberian war zone. Antrhopological Quarterly, 78 (2): 403-430. 